\title{
More of the same: Allopatric humpback whale populations share acoustic repertoire
}

\author{
Michelle EH Fournet ${ }^{\text {Corresp.. }}{ }^{1,2}$, Lauren Jacobsen ${ }^{3}$, Christine M Gabriele ${ }^{4}$, David K Mellinger ${ }^{2}$, Holger Klinck ${ }^{3}$ \\ 1 Department of Fisheries and Wildlife, Oregon State University, Corvallis, Oregon, United States \\ ${ }^{2}$ Cooperative Institute of Marine Resource Studies, Oregon State University and NOAA Pacific Marine Environmental Laboratory, Newport, OR, United \\ States of America \\ 3 Bioacoustics Research Program, Cornell Lab of Ornithology, Cornell University, Ithaca, New York, United States \\ 4 Humpback Whale Monitoring Program, Glacier Bay National Park and Preserve, Gustavus, Alaska, United States \\ Corresponding Author: Michelle EH Fournet \\ Email address: michelle.fournet@oregonstate.edu
}

Background. Humpback whales (Megaptera novaeangliae) are a widespread, vocal baleen whale best known for producing song, a complex, repetitive, geographically distinct acoustic signal sung by males, predominantly in a breeding context. Humpback whales worldwide also produce non-song vocalizations ("calls") throughout their migratory range, some of which are stable across generations. Methods. We looked for evidence that temporally stable call types are shared by two allopatric humpback whale populations while on their northern hemisphere foraging grounds in order to test the hypothesis that some calls, in strong contrast to song, are innate within the humpback whale acoustic repertoire. Results. Despite being geographically and genetically distinct populations, humpback whales in Southeast Alaska (North Pacific Ocean) share at least five call types with conspecifics in Massachusetts Bay (North Atlantic Ocean). Discussion. This study is the first to identify call types shared by allopatric populations, and provides evidence that some call types may be innate. 
1 More of the same: allopatric humpback whale populations share acoustic repertoire

2 Michelle E. H. Fournet ${ }^{1,2}$, Lauren Jacobsen ${ }^{3}$, Christine M. Gabriele ${ }^{4}$, David K. Mellinger ${ }^{2}$, 3 Holger Klinck ${ }^{3}$

4

$5 \quad{ }^{1}$ Department of Fisheries and Wildlife, Oregon State University, Corvallis, OR 97331

$6{ }^{2}$ Cooperative Institute for Marine Resources Studies, Oregon State University and NOAA Pacific Marine

7 Environmental Laboratory, Newport, OR, 97365

$8{ }^{3}$ Bioacoustics Research Program, Cornell Lab of Ornithology, Cornell University, Ithaca, NY, 14850

$9 \quad{ }^{4}$ Humpback Whale Monitoring Program, Glacier Bay National Park and Preserve, Gustavus, AK 99826

11

12

Corresponding author:

Michelle E. H. Fournet $\mathbf{1 , 2}$

14

15

16

Email Address:

17 michelle.fournet@gmail.com 


\section{Abstract}

19 Background. Humpback whales (Megaptera novaeangliae) are a widespread, vocal baleen 20 whale best known for producing song, a complex, repetitive, geographically distinct acoustic 21 signal sung by males, predominantly in a breeding context. Humpback whales worldwide also 22 produce non-song vocalizations ("calls") throughout their migratory range, some of which are 23 stable across generations. Methods. We looked for evidence that temporally stable call types are 24 shared by two allopatric humpback whale populations while on their northern hemisphere 25 foraging grounds in order to test the hypothesis that some calls, in strong contrast to song, are 26 innate within the humpback whale acoustic repertoire. Results. Despite being geographically and genetically distinct populations, humpback whales in Southeast Alaska (North Pacific Ocean) share at least five call types with conspecifics in Massachusetts Bay (North Atlantic Ocean).

Discussion. This study is the first to identify call types shared by allopatric populations, and provides evidence that some call types may be innate. \\ 32 Introduction}

33 The study of acoustic signaling is a valuable tool for investigating animal behavior across a 34 broad range of taxa (Brockelman \& Schilling 1984, Gannon 2008, Pijanowski et al. 2011, Clink 35 et al. 2018). Sounds produced by animals can be systematically measured and compared, as can 36 patterns of vocal behavior made in association with critical activities such as breeding, foraging, or socializing. Acoustic monitoring allows for broad-scale observations of animals across space and time and between populations (Mann \& Lobel 1998, Cerchio et al. 2001, Risch et al. 2007, Potvin et al. 2011). When coupled with what is known about genetics, population structure, and behavior, acoustic analyses become powerful tools for investigating the factors that shape communication signals.

Drivers of acoustic repertoires vary between taxa and species. While anatomy is a restricting 44 force driving sound production, genetic, neurological, and environmental drivers also influence acoustic repertoires and vocal plasticity. For acoustic communication to be effective, a sound must be detectable within its acoustic habitat and sufficiently convey information to a receiver. As such, acoustic communicators have evolved adaptations to couple the acoustic properties of 
49 maximize fitness (Slater 1983, Boncoraglio \& Saino 2006). As a result, within the repertoire of 50 most, if not all, sound-producing vertebrates are a collection of innate (i.e., unlearned) calls that 51 are exercised independently of vocal learning and persist across generations (e.g., Domestic 52 Fowl Gallus gallus and other species in the order Galliformes (Konishi 1963, Matsunaga \& 53 Okanoya 2009), white-handed gibbons Hylobates lar (Brockelman \& Schilling 1984), New 54 Zealand fur seals Arctocephalus forsteri (Page et al. 2001)). A smaller subset of taxa - most 55 notably passerine songbirds - exhibit a combination of learned and unlearned vocal signals, 56 which persist over time within a population (Baker \& Jenkins 1987, Vicario 2004, Matsunaga \& 57 Okanoya 2009, Zann 2010). Some mammals including pinnipeds (taxonomic group including 58 seals and sea lions), and cetacean species (taxonomic group including whales, dolphins, and 59 porpoises) are also capable of vocal learning as indicated by vocal imitation or improvisation 60 (Tyack \& Sayigh 1997, Poole et al. 2005, Petkov \& Jarvis 2012). What is less well described 61 among mammalian vocal learners, however, is the coupling of stable sound types, which may be 62 innate, with a dynamically changing repertoire of sound types whose variation appears to be 63 culturally driven. Cetaceans, and specifically humpback whales (Megaptera novaeangliae), may 64 be the best example of a taxon which exhibits this coupling of highly stable calls types and 65 dynamically shifting vocal behaviors (Payne \& Payne 1985, Tyack \& Sayigh 1997, Rekdahl et 66 al. 2013, Fournet et al. 2015a, Fournet 2018).

67

68 Humpback whales are a migratory baleen whale with a cosmopolitan distribution. Generally, 69 humpback whales migrate between low-latitude breeding and calving grounds and high-latitude 70 foraging grounds (Clapham et al. 1999). Their vocal behaviors are geographically and seasonally stratified. Primarily on breeding grounds and migratory corridors, but also to a lesser extent on

72 foraging grounds, male humpback whales produce a long elaborate, and repetitive vocal display 73 known as 'song', (Payne \& McVay, 1971; Gabriele \& Frankel, 2002; Stimpert et al., 2012;

74 Dunlop \& Noad, 2016; Herman, 2017). Songs are highly structured and acoustically complex, 75 and are culturally transmitted between males within a single breeding region (Cerchio et al. 2001, Mercado et al. 2005, Herman et al. 2013, Herman 2017). Song structure changes rapidly over time (1-2 years) (Payne \& Payne 1985, Noad et al. 2000, Parsonset al. 2008). Further, geographic variation in song between regions is typical (Winn et al. 1981, Cerchio et al. 2001, 
79 Parsons et al. 2008), with song sharing only occurring between regions that share individuals

80 (Cerchio et al. 2001, Mercado et al. 2005, Garland et al. 2015b, Herman 2017).

81

82 Humpback whales of both sexes and across the migratory range also produce a series of 83 vocalizations ("calls") independently of song (Silber 1986, Dunlop et al. 2008, Stimpert et al.

84 2011). Calls occur in isolation or in short bouts and occasionally appear as song units (Rekdahl 85 et al. 2013, 2015). Call use varies based on social and behavioral context; some calls facilitate 86 intra-group interactions, while other calls are specific to foraging contexts (Stimpert et al. 2007, 87 Dunlop et al. 2008, Wild \& Gabriele 2014, Fournet et al. 2018). Unlike song, many calls are 88 stable over time. The most commonly produced call types in the east Australian migratory 89 corridor, making up $64 \%$ of the call detected in one study, are stable over 7-11 year time periods 90 (Rekdahl et al. 2013), while in Southeast Alaska, at least 16 call types, including all described 91 call types to date, persist in the call repertoire for decades and across generations (Fournet et al. 92 2015a, Fournet 2018).

93

94 Call longevity across generations is an indication that some call types may be fixed within the 95 humpback whale repertoire. Identifying the same stable call types in other, unrelated populations 96 would provide further evidence that humpback whales may be anatomically or behaviorally 97 predisposed toward the production of certain sounds. Qualitative comparisons have been made of 98 calls produced in the North Pacific (Southeast Alaska, USA), South Pacific (East Australia), 99 North Atlantic (Massachusetts Bay, USA) and South Atlantic (Coastal Angola, Africa) with the 100 general agreement that global humpback whale populations produce some similar call types 101 (Dunlop et al. 2007, Stimpert et al. 2011, Fournet, et al. 2015, Rekdahl et al. 2016), but no 102 formal comparison of call types between populations has been thus far attempted. 103

104 To test the hypothesis that some calls types are inherent to humpback whales, we looked for 105 evidence of shared call types in the call repertoire of two allopatric humpback whale populations 106 on their northern latitude foraging grounds, one in the North Atlantic and one in the North 107 Pacific. Based on genetic analyses it is estimated that global humpback whale populations last 108 shared a maternal ancestor in the Miocene, approximately 5 Mya, and that discrete lineages split 109 2-3 Mya (Baker et al. 1993). In the northern hemisphere, humpback whales in the Atlantic and 
110 Pacific Ocean are geographically separated by the North American continent and are genetically

111 isolated from one another (Valsecchi et al. 1997, McComb et al. 2003). Cultural exchange of

112 acoustic signals between the two populations is extremely unlikely based on this geographic

113 barrier and known migratory patterns. Thus, a shared acoustic repertoire would indicate that

114 individual signals may be fixed within the species and conserved with time, rather than socially

115 learned. We hypothesized that call types that are stable across multiple generations on a North

116 Pacific foraging ground would also be present in the humpback whale call repertoire on a North

117 Atlantic foraging ground.

118

119 Methods

120 Data collection

121 We compiled acoustic datasets from two humpback whale foraging grounds in the North Pacific 122 and North Atlantic. Acoustic data from Southeast Alaska (SEAK: North Pacific) were collected 123 using passive acoustic recording devices during summer months (June-August) in Frederick

124 Sound in 1976 and Glacier Bay National Park and Preserve (GBNPP) in 2007, and 2008.

125 Acoustic recordings were also collected using passive acoustic recording devices deployed

126 during summer months in Massachusetts Bay (MB; North Atlantic) in 2008 (Figure 1, Table 1).

127 Acoustic recordings from Frederick Sound, SEAK were opportunistically collected with a dip

128 hydrophone from a drifting vessel and were of variable duration (32-94 minutes). Acoustic

129 recordings from GBNPP made in 2007 and 2008 were collected from a cabled hydrophone in

130 Bartlett Cove (Figure 1) with a 30-seconds-per-hour recording cycle (Wild \& Gabriele 2014).

131 Data from GBNPP were reviewed by U.S. Navy acousticians to characterize the content of each

132 sound sample. Data from MB were collected as part of a long-term monitoring project in that

133 region (see also Hatch et al. 2012). Recordings were made using an array of marine autonomous

134 recording units (MARUs; Calupca et al. 2000; Table 1). Research analysts from the Bioacoustics

135 Research Program at Cornell Laboratory of Ornithology reviewed array recordings and noted the

136 presence or absence of humpback whale calls on each element. We randomly subset 60 hours of

137 two-channel acoustic data from the array for analysis (Figure 1). Sound samples from both

138 regions were analyzed only if they were known to contain humpback whale calls.

139

140 Data Processing and Analysis 
141 Recordings from SEAK were originally sampled at $44.1 \mathrm{kHz}$ and were resampled at a rate of 2

$142 \mathrm{kHz}$ for consistency with data from MB (Table 1); all recordings were made with 16 bit

143 resolution. Once resampled, recordings were comparable, though not completely equivalent.

144 Differences in recording equipment and conditions may manifest in extracted feature values;

145 however when paired with robust call inclusion criteria and our choice of feature extraction

146 methodology (see below) call classification is robust to these differences. Spectrograms of

147 acoustic recordings were created with Raven Pro 1.5 (Cornell Lab of Ornithology, Ithaca, NY)

148 using an FFT length of 1046, a 30 s window length, Hann window, 75\% overlap, for a frequency

149 resolution of $2.75 \mathrm{~Hz}$ and constrained to the $10 \mathrm{~Hz}$ to $1 \mathrm{kHz}$ frequency range to facilitate

150 analysis. Recordings were manually reviewed by experienced observers familiar with the

151 humpback whale call repertoire. All calls were annotated in the time-frequency domain and

152 salient acoustic features were extracted for quantitative classification in Raven Pro (Table 1).

153 Aggregate entropy was also extracted for each sound (Table 1). In some cases differences in

154 aggregate entropy reflect variation in recording conditions; however, where considerable

155 differences in acoustic structure exist (e.g. between call types) aggregate entropy is one of the

156 few acoustic measurements capable of discriminating between structurally 'simple' calls (see

157 droplets in Figure 2b) and structurally 'complex' calls (see whups Figure 2d). For this reason

158 when recording conditions vary, aggregate entropy is still relevant for discriminating between-

159 call type differences, which are generally more contrasting. In this study data exploration did not

160 reveal any significant differences in aggregate entropy related to recording location or year.

161 For harmonic sounds, measurements of the start- and end-frequencies were made on the

162 fundamental frequency. For amplitude-modulated sounds containing a broadband component,

163 measurements were made on the lowest-frequency component of the call (Dunlop et al. 2007 ,

164 Rekdahl et al. 2013). Frequency parameters were log-transformed to account for the mammalian

165 perception of pitch (Table 2) (Richardson et al., 1995; Dunlop et al., 2007; Fournet et al., 2015b);

166 although humpback pitch perception has not been studied experimentally, humpback ear

167 morphology suggests that their sound reception is, like other mammals, approximately

168 logarithmic (Southall et al., 2007).

169 Time-frequency parameters were input into a Principal Component Analysis (PCA) in order to

170 aggregate correlated variables for classification and comparative analyses ( $\mathrm{R}$, psych package). A

171 varimax rotation was applied (Table 2) to maximize loading and facilitate variable interpretation 
172 (Cerchio \& Dahlheim 2001, Dunlop et al. 2007). By pairing PCA values with traditional acoustic

173 measurements during classification analyses we account for the broad structure of the call (e.g.

174 broadband and high frequency vs. narrowband and high frequency) as well as the fine-scale

175 acoustic features. Boxplots (median, first, and third quartile PCA values) were generated in R

176 using the ggplot2 package (Wickam, 2016) to qualitatively compare differences in call structure

177 between ocean basins.

178

179 Signal-to-noise ratios (SNRs) were calculated for each acoustic sample by measuring the in-band 180 power contained in a one-second sound sample directly preceding each call; this value was then 181 subtracted from the in-band power measured of the call of interest to get the band-limited SNR 182 value. Calls in this study were only included if they had a SNR of $10 \mathrm{~dB}$ or higher (Dunlop et al. 183 2007, Rekdahl et al. 2016).

184

185 Using the existing SEAK call catalog as a reference, each acoustic sample was assigned an $a$ 186 priori call type based on aural and visual call features. Because the goal of this study was to 187 investigate the potential for call types to be fixed within this species, only call types that persist 188 across generational timescales that could be detected given a $2 \mathrm{kHz}$ sampling rate were included 189 in this study; this included droplet, growl, swop, teepee, whup, and feeding calls (Fournet et al. 190 2015a, Fournet 2018). Droplets, swops, and teepees are short-duration pulsed calls that typically 191 occur in short repeated sequences. Growls and whups, by contrast, are harmonic and amplitude192 modulated calls that are generally not repeated (Wild and Gabriele, 2014, Fournet et al. 2015a, 193 Fournet 2018). Feeding calls are stereotyped highly-tonal, low-complexity calls that have been

194 closely associated with herring foraging in SEAK humpback whales (Cerchio and Dalheim 2001, 195 Fournet et al. 2018b). Acoustic samples that were qualitatively different than previously

196 described call types were classified as 'unknown' and no further attempts for classification were 197 made. Initial data exploration found no significant differences in acoustic parameters of calls 198 recorded in GBNPP and calls recorded in Frederick Sound; calls from SEAK were pooled for 199 analysis.

200

201 Quantitative classification methods were identical to those used by Fournet (2018a), with the 202 exception that all predictor variables were extracted in Raven Pro. For consistency with other 
203 humpback whale call classification studies, calls were classified through the use of a

204 Classification and Regression Tree analysis (CART, rPart package; R Core Development Team, 205 2012) and a random forest analysis (randomForest package; Liaw and Weiner, 2002) using the 206 methodologies described by Rekdahl et al. $(2013,2016)$. The combination of CART and random 207 forest analyses to validate human call type assignment has emerged as the preferable method for 208 classification of humpback calls (as well as other cetaceans; Garland et al. 2015a). CART 209 analyses are robust to outliers, non-normal and non-independent data, and random forest 210 analyses improves accuracy using a bootstrapping method to generate a level of uncertainty for 211 each classification tree, rather than a single classification tree (Breiman et al. 1984, Rekdahl et 212 al. 2013, 2016). In the CART analysis the Gini index was used to assess the "goodness-of-split" 213 for each node in the tree. All variables were considered independently and ranked, and the 214 splitting variable that minimized splitting error was selected (Beiman et al. 1984, Rekdahl et al. 215 2013, 2016). Terminal nodes were set to have a minimum sample size of ten. Trees were 216 overgrown and then pruned upward until reaching the tree with the lowest misclassification rate 217 (Breiman et al. 1984). A total of 1,000 trees were grown for the random forest analysis. Predictor 218 variables included salient acoustic features as well as two rotated principal components (PC) that 219 aggregated correlated acoustic variables (Dunlop et al. 2007); a detailed description of predictor 220 variables can be found in Table 2. Quantitative classification assignments were compared to $a$ 221 priori call type assignments to validate observer classification. Major discrepancies in call type 222 assignment were re-reviewed by at least two observers. Calls were excluded if observers were 223 not in agreement. If observers were in agreement about call type assignment than the a priori 224 classification was deemed 'correct'. All analyses were conducted in R version 3.3.3 (R, 2013).

226 To assess differences in acoustic parameters between calls from MB and SEAK populations, we 227 summarized and compared PC values for all call types that exhibited stability between regions. 228 Comparative analyses were made based on a priori classification. Humpback whales in both 229 SEAK and MB exhibit seasonal movements throughout foraging grounds during summer months 230 (Baker, 1985, Straley et al. 1993, Weinrich, 1998, Payne et al., 1986, Schilling et al., 1992), 231 reducing the likelihood of their repeated acoustic capture on hydrophones, which have a finite 232 listening range. Additionally, a random subset of acoustic data spanning summer months in MB 233 was selected for analysis in order to reduce the likelihood of repeated capture of individuals. 
234 Also, the temporal breadth of recordings made in in SEAK (Table 1) make the probability of

235 documenting only a small subset of individuals from this region unlikely. However, because data

236 were collected passively without concomitant visual observations the number of vocalizing

237 individuals is unknown. For this reason the independence of each data point cannot be confirmed

238 and statistical tests pertaining to population level differences are inappropriate.

239

\section{Results}

241 A total of 411 sounds fitting the inclusion criteria were classified to one of six known call types

242 (droplets, growls, feeding calls, swops, teepees, whups; Fournet et al. 2015b); 191 calls were

243 collected across 10 recording days from Massachusetts Bay (MB), and 220 calls were collected

244 across 76 sample days from Southeast Alaska (SEAK; Table 1, Table 3). Drops, growls, swops,

245 teepees, and whups were found in both populations (Figure 2, Table 3); feeding calls were

246 detected only in SEAK. A Bartlett's Test of Sphericity

247 indicated that data was suitable for factorial analysis $\left(\chi^{2}=18106.78\right.$, d.f. $\left.=55, p<0.00001\right)$; this

248 was confirmed by a Kaiser-Meyer-Olkin value of 0.61 . The first rotated component (PC1)

249 corresponded most closely to aggregate entropy, bandwidth, and upper frequency (proportion

250 variance explained $=0.51)$, meaning that as PC1 increases, the calls grow more complex, grow

251 broader-band, and extend to higher frequencies. The second rotated component (PC2)

252 corresponded most closely to lower frequency, start frequency, and peak frequency (proportion

253 variance explained $=0.49)$, meaning that as PC2 increases, calls grow higher in pitch overall, but

254 not necessarily more broadband or complex. Neither component was strongly affiliated with

255 duration or bout in this analysis, meaning that the PC variables in this analysis do not represent

256 temporal variability.

257

258 CART call type assignment and a priori call type assignment were in agreement $82 \%$ of the time

$259(\mathrm{n}=335 / 411$, Table 4$)$. In descending order of importance, splitting variables for CART

260 classification were bandwidth, bout, center frequency, duration, end frequency, aggregate

261 entropy, lower frequency, and PC1. The random forest analysis correctly classified most of the

262 calls (out-of-bag error rate $=23 \%$ ). The variables most important for splitting decisions in the

263 random forest analysis in were bout, end frequency, duration, aggregate entropy, lower

264 frequency, PC1, PC2, and frequency trend, in descending order of importance. Whups were the 
265 most commonly misclassified calls (Table 4); in the CART analysis whups were mistaken for

266 growls $38 \%$ of the time $(\mathrm{n}=22)$. Observers validated call type assignment for most whup calls

$267(95 \%, \mathrm{n}=57)$; three calls were omitted due to classification incongruity.

268

269 PC1 values were higher in SEAK than MB for all call types except for growls, indicating that 270 calls from SEAK were generally broader band and exhibited higher levels of complexity (Table

271 3, Figure 3). PC2 values were higher in SEAK than MB for droplet and teepee calls (Table 3, 272 Figure 4), indicating that calls from SEAK were generally higher pitched than calls from MB.

273

\section{Discussion}

275 This is the first study to describe call types shared by allopatric humpback whale populations.

276 Evidence that temporally stable call types are shared between Southeast Alaska (SEAK) and

277 Massachusetts Bay (MB) humpback whale populations supports the hypothesis that a portion of

278 the call repertoire may be fixed in this species.

279

280

In SEAK there are six call types that are stable over generational time (Fournet 2015b) that have

281 average bandwidths between $10-1,000 \mathrm{~Hz}$ : droplets, growls, swops, teepees, whups, and

282 feeding calls. Misclassification was low for all call types, except for whups, which were

283 commonly classified as growls. Misclassification of these call types is unsurprising, as the only

284 distinguishing acoustic feature between growls and whups is a terminal upsweep, which

285

286

287

288

289

290

291

292

293 Within-call variation, related to individual anatomy, behavioral or environmental context can be

294 found within most if not all vertebrate vocalizers, and does not contradict placement into call

295 classes or types (Ford 1991, Tyack et al. 1997, Deecke et al. 2000, Tibbets et al. 2007, Rekdahl 
296 et al. 2013). In this study, despite otherwise high classification agreement, there were some

297 differences in call type parameters between populations. The increased PC1 values found in

298 SEAK versus MB may be recording artifacts. The ambient sound conditions in SEAK are

299 significantly different than MB (Kipple \& Gabriele 2003, Hatch et al. 2008, Haver et al. 2018).

300 Recordings from Frederick Sound were made in the absence of vessel noise, and recordings

301 made in GBNPP were made in the presence of limited vessel traffic. By contrast, the

302 hydrophones in MB were located within a shipping lane that services Boston Harbor, which is

303 among the busiest harbors on the North American east coast. For this reason, vessel noise was

304 recorded simultaneously with almost all calls recorded in MB (Figure 2). Overlapping ambient

305 sounds - including vessel noise, which is common throughout the $10-1,000 \mathrm{~Hz}$ band (Wenz

306 1962) - may have masked fine-scale acoustic features, resulting in decreased aggregate entropy

307 measurements in MB calls. Similarly, vessel noise in MB may have masked upper-frequency

308 portions of calls, which contain less energy and attenuate faster and are thus more easily

309 obscured by overlapping ambient sound. Systematic differences in frequency between droplets

310 and teepees in SEAK vs. MB (Table 3) may be related to factors such as motivational state

311 (Rehn et al. 2011, Dunlop 2017), body size (May-Collado et al. 2007), and/or ambient noise

312 (Parks et al. 2007, Di'Iorio \& Clark 2010, Parks et al. 2016), but a dedicated research effort that

313 includes direct observation and identification of individuals would be required to address this

314 question.

315

316 With one exception, call types of interest from SEAK were also found in MB. The notable

317 exception was the SEAK feeding call. Feeding calls are highly stereotyped, tonal calls, with a

318 fundamental frequency of $\sim 500 \mathrm{~Hz}$ that occur when humpback whales in Southeast Alaska

319 forage on Pacific herring (Clupea palisii) (D'Vincent et al. 1985, Sharpe 2001, Fournet et al.

320 2018). Herring are a primary food source for humpback whales in Southeast Alaska (Krieger \&

321 Wing 1984, D’Vincent et al. 1985, Dolphin 1988), whereas in MB humpback whales feed

322 primarily on sand lance (Ammodytes spp.), a calorie-dense prey species that burrows in the sandy

323 substrate (Overholtz \& Nicolas 1979, Hain et al. 1995, Friedlaender et al. 2009). The absence of

324 feeding calls in MB may be attributed to their focus on forage species other than herring. 
326 Droplets, growls, swops, teepees, and whups were present in the call repertoire of both

327 humpback whale populations. Evidence of the same calls in allopatric populations supports the

328 hypothesis that a portion of the humpback whale call repertoire is innate. Many non-passerine

329 bird species such as doves (Streptopelia $\mathrm{sp}$.) produce highly stereotyped calls instinctively (Lade

$330 \&$ Thorpe 1964), and as a result allopatric dove populations of the same species, even those

331 separated by great distances, show no significant difference in call types (de Kort et al. 2002).

332 Ornate chorus frogs (Microhyla fissipes) produce advertisement calls independently of vocal

333 learning that are aurally indistinguishable between geographic regions, and that vary only

334 minutely with genetic distance (Lee et al. 2016). Genetic predetermination of calls is common

335 across taxa, including zebra finches (Taeniopygia guttata; Forstmeier et al. 2009), fur seals

336 (Antarctic, Arctocephalus gazella, subantarctic, A. tropicalis, and New Zealand, A. forsteri; Page

337 et al. 2001), and Spheniscus penguins (Thumser \& Ficken 1998). Call type stereotypy in these

338 species is generally multi-generational and geographically widespread. In humpback whales,

339 identifying call types that are multi-generational, and persist in geographically and genetically

340 discrete populations provides strong evidence that these call types are innate.

341

342 If the call types described in this study are innate to humpback whale worldwide, as we

343 hypothesize, then it should be possible to build an automated acoustic detector that could be run

344 on datasets from across ocean basins and years to confirm the presence of humpback whales at

345 previously unknown regions or times. The ability to confidently credit particular vocalizations to

346 humpback whales in the absence of visual confirmation allows for broader spatial and temporal

347 monitoring with significantly lower effort and cost (see also Stimpert et al. 2011).

348

349 For calls to be conserved within the call repertoire of genetically and geographically discrete 350 populations is an indication that they play an important role in humpback whale life history by

351 increasing individual fitness in some capacity. It has been proposed that in Southeast Alaska the

352 whup call serves a contact function (Wild \& Gabriele 2014), and the analogous "wop" call of

353 east Australia may facilitate communication between cows and calves (Dunlop et al. 2008).

354 There is also evidence that droplets, swops, and teepees are used for close range communication

355 on foraging grounds (Fournet 2014), and similar pulsed calls may facilitate affiliation or

356 disaffiliation in groups during migration (Dunlop et al, 2008). These broad contextual 
357 descriptions, suggest that these calls serve a vital function or functions. The fixed nature of calls

358 stands in marked contrast to humpback whale song, which is geographically discrete, changes

359 rapidly, and is culturally transmitted rather than innate (Payne \& Payne 1985, Noad et al. 2000,

360 Cerchio et al. 2001). Thus it seems that the humpback whale vocal repertoire is composed of

361 both fixed and adaptable calls. Dedicated research pairing the call types described in this study

362 with behaviors and social context will further the understanding the role of calls in the acoustic

363 ecology of humpback whales.

364

365 Conclusions

366 This study demonstrates that some humpback whale call types are shared between

367 geographically discrete northern latitude foraging grounds. This feature lend support to the

368 hypothesis that some calls may be innate, and in strong contrast to song, are not culturally

369 transmitted. Natural next steps include a global comparison of call repertoires between allopatric

370 populations and across the migratory range, with particular attention paid to change or stability at

371 various temporal and geographic scales.

372

\section{Acknowledgements}

374 The authors wish to acknowledge Dr. Roger Payne for the use of the recordings from Southeast

375 Alaska in 1976. We thank David Culp for data processing support, and Katherine Indeck for

376 statistical support. We also wish to thank the National Park Service for its long term commitment

377 to acoustic monitoring in Glacier Bay National Park, and to the Cornell Bioacoustics Research

378 Program for use of the data from Massachusetts Bay. This is PMEL contribution number 4784.

379

380

381 


\section{Works Cited}

383

384

Baker AJ, Jenkins PF (1987) Founder effect and cultural evolution of songs in an isolated

385

386 population of chaffinches, Fringilla coelebs, in the Chatham Islands. Anim Behav 35:17931803

387

Baker CS, Herman LM, Perry A, Lawton WS, Straley JM, Straley JH (1985) Population

388

389

Characteristics and Migration of Summer and Late-Season Humpback Whales Megaptera

390 novaeangliae in Southeastern Alaska. Mar Mammal Sci 1:304-323

Baker CS, Perry a, Bannister JL, Weinrich MT, Abernethy RB, Calambokidis J, Lien J, 391

392

393

394

395

396

Lambertsen RH, Ramírez JU, Vasquez O (1993) Abundant mitochondrial DNA variation and world-wide population structure in humpback whales. Proc Natl Acad Sci U S A 90:8239-8243

Boncoraglio G, Saino N. (2007) Habitat structure and the evolution of bird song: a meta-analysis of the evidence for the acoustic adaptation hypothesis. Func Ecol 21:134-42.

Breiman L, Friedman JH, Olshen RA, and Stone CJ (1984) Classification and regression trees.

397

398

399 Wadsworth International Group, Belmont, CA

Brockelman WY, Schilling D (1984) Inheritance of stereotyped gibbon calls. Nature 312:634636

400

Calupca TA, Fristrup KM, Clark CW (2000) A compact digital recording system for autonomous 401

402 bioacoustic monitoring. J Acoust Soc Am 108:2582-2582

403

Cerchio S, Dahlheim M (2001) Variation in feeding vocalizations of humpback whales

404 Megaptera novaeangliae from Southeast Alaska. Bioacoustics 11:277-295

Cerchio S, Jacobsen JK, Norris TF (2001) Temporal and geographical variation in songs of

405 humpback whales, Megaptera novaeangliae: synchronous change in Hawaiian and Mexican

406 breeding assemblages. Anim Behav 62:313-329

407

Clapham PJ, Mead JG, Gray M (1999) Megaptera novaeangliae. Mamm Species:1-9

408

Clink DJ, Crofoot MC, Marshall AJ (2018) Application of a semi-automated vocal fingerprinting 409 approach to monitor Bornean gibbon females in an experimentally fragmented landscape in Sabah, Malaysia. Bioacoustics DOI: 10.1080/09524622.2018.1426042

D’Vincent CG, Nilson RN, Hanna RE (1985) Vocalization and coordinated feeding behavior of the humpback whale in Southeastern Alaska. Sci Reports Whales Res Inst 36:41-47 
413 DeeckeVB, Ford JKB, and Spong P. (2000) Dialect change in resident killer whales:

414 Implications for vocal learning and cultural transmission. Anim. Behav. 40: 629- 638.

415 Di' Orio L Clark CW (2010) Exposure to seismic survey alters blue whale acoustic

416 communication. Biol Lett 6:334-335

417 Dolphin WF (1988) Foraging dive patterns of humpback whales, Megaptera novaeangliae, in 418 southeast Alaska: a cost-benefit analysis. Can J Zool 66:2432-2441

419 Doyle LR, McCowan B, Hanser SF, Chyba C, Bucci T, Blue JE (2008) Applicability of 420 Information Theory to the Quantification of Responses to Anthropogenic Noise by 421 Southeast Alaskan Humpback Whales. Entropy 10:33-46

422 Dunlop RA (2016) The effect of vessel noise on humpback whale, Megaptera novaeangliae, 423 communication behaviour. Anim Behav 111:13-21

424 Dunlop RA (2017) Potential motivational information encoded within humpback whale non425 song vocal sounds. J Acoust Soc Am 141:2204-2213

426 Dunlop RA, Cato DH, Noad MJ (2008) Non-song acoustic communication in migrating 427 humpback whales (Megaptera novaeangliae). Mar Mammal Sci 24:613-629

428 Dunlop RA, Noad MJ (2016) The "risky" business of singing: tactical use of song during joining 429 by male humpback whales. Behav Ecol Sociobiol 70:2149-2160

430 Dunlop RA, Noad MJ, Cato DH, Stokes D (2007) The social vocalization repertoire of east 431

432 Australian migrating humpback whales (Megaptera novaeangliae). J Acoust Soc Am

433 Ford JKB (1991) Vocal traditions among resident killer whales ( Orcinus orca ) in coastal waters 434 of British Columbia. Can. J. Zool. 69, 1454-1483

435 Forstmeier W, Burger C, Temnow K, Derégnaucourt S (2009) The genetic basis of zebra finch 436 vocalizations. Evolution 63:2114-2130

437 Fournet M (2014) Social calling behavior of Southeast Alaskan humpback whales (Megaptera 438 novaeangliae): classification and context. Master's Thesis, Oregon State University 439 Fournet MEH (2018a) Humpback whale (Megaptera novaeangliae) calling behavior in 440 Southeast Alaska: a study in acoustic ecology and noise. PhD Dissertation, Oregon State 441 University. DOI: 10.13140/RG.2.2.35810.43200

442 Fournet MEH, Culp D, Gabriele CM, Sharpe FA, Payne RS, Mellinger DK, Klinck H (2015a) 443 Temporal stability of non-song vocalizations in North Pacific humpback whales (Megaptera 444 novaeangliae) at the decadal scale. 21st Biennial Conference on the Biology of Marine 
445

446

447

448

449

450

451

452

453

454

455

456

457

458

459

460

461

462

463

464

465

466

467

468

469

470

471

472

473

474

475

Mammals, San Francisco. San Francisco, CA

Fournet MEH, Gabriele CM, Sharpe F, Straley JM, Szabo A (2018b) Feeding calls produced by solitary humpback whales. Mar Mammal Sci 1-15

Fournet MEH, Szabo A, Mellinger DK (2015b) Repertoire and classification of non-song calls in Southeast Alaskan humpback whales (Megaptera novaeangliae). J Acoust Soc Am 137:110

Friedlaender AS, Hazen EL, Nowacek DP, Halpin PN, Ware C, Weinrich MT, Hurst T, Wiley D (2009) Diel changes in humpback whale Megaptera novaeangliae feeding behavior in response to sand lance Ammodytes spp. behavior and distribution. Mar Ecol Prog Ser 395:91-100

Gabriele C, Frankel A (2002) The Occurrence and Significance of Humpback Whale Songs in Glacier Bay, Southeastern Alaska. Arct Res United States 16:42-47

Gannon DP (2008) Passive Acoustic Techniques in Fisheries Science: A Review and Prospectus. Trans Am Fish Soc 137:638-656

Garland EC, Castellote M, and BerchokCL (2015a) Beluga whale (Delphinapterus leucas ) vocalizations and call classification from the eastern Beaufort Sea population. J. Acoust. Soc. Am. 137: 3054-3067

Garland EC, Goldizen AW, Lilley MS, Rekdahl ML, Garrigue C, Constantine R, Hauser ND, Poole MM, Robbins J, Noad MJ (2015b) Population structure of humpback whales in the western and central South Pacific Ocean as determined by vocal exchange among populations. Conserv Biol 29:1198-1207

Hain JHW, Ellis SL, Kenney RD, Clapham PJ, Gray BK, Weinrich MT, Babb IG (1995) Apparent Bottom Feeding by Humpback-Whales on Stellwagen Bank. Mar Mammal Sci $11: 464-479$

Hatch LT, Clark,CW, Van Parijs SM, Frankel AS, Ponirakis D (2012) Quantifying loss of acoustic communication space for right whales in and around a U. S. National Marine Sanctuary. Conserv Biol 26:983-994

Hatch L, Clark C, Merrick R, Parijs S Van, Ponirakis D, Schwehr K, Thompson M, Wiley D (2008) Characterizing the Relative Contributions of Large Vessels to Total Ocean Noise Fields: A Case Study Using the Gerry E. Studds Stellwagen Bank National Marine Sanctuary. Environ Manage 42:735-752 
476 Haver SM, Gedamke J, Hatch LT, Dziak RP, Parijs S Van, McKenna MF, Barlow J, Berchok C,

477

478

479

480

481

482

483

484

485

486

487

488

489

490

491

492

493

494

495

496

497

498

499

500

501

502

503

504

505

506

DiDonato E, Hanson B, Haxel J, Holt M, Lipski D, Matsumoto H, Meinig C, Mellinger DK, Moore SE, Oleson EM, Soldevilla MS, Klinck H (2018) Monitoring long-term soundscape trends in U.S. Waters: The NOAA/NPS Ocean Noise Reference Station Network. Mar Policy 90:6-13

Herman LM (2017) The multiple functions of male song within the humpback whale (Megaptera novaeangliae) mating system: review, evaluation, and synthesis. Biol Rev 92:1795-1818

Herman LM, Pack AA, Spitz SS, Herman EYK, Rose K, Hakala S, Deakos MH (2013)

Humpback whale song: Who sings? Behav Ecol Sociobiol 67:1653-1663

Konishi M (1963) The Role of Auditory Feedback in the Vocal Behavior of the Domestic Fowl. Ethology 20:349-367

Kipple B, Gabriele C (2003) Glacier Bay underwater noise-2000 through 2002: Report to Glacier Bay National Park Tech Rep NSWCCD-71-TR-2004/521, Naval Surface Warfare Center, Bremerton, WA

Kort SR de, Hartog PM den, Cate C ten (2002) Diverge or merge? The effect of sympatric occurrence on the territorial vocalizations of the vinaceous dove Streptopelia vinacea and the ring-necked dove S. capicola. J Avian Biol 33:150-158

Krieger KJ, Wing BL (1984) Hydroacoustic surveys and identification of humpback whale forage in Glacier Bay, Stephens Passage, and Frederick Sound, southeastern Alaska, summer 1983. NOAA Tech Memo NMFS-F/NWC-66 60p 1984:66

Lade BI, Thorpe WH (1964) Dove songs as innately coded patterns of specific behaviour. Nature 202:366-368

Lee KH, Shaner PJL, Lin YP, Lin SM (2016) Geographic variation in advertisement calls of a Microhylid frog - testing the role of drift and ecology. Ecol Evol 6:3289-3298

Mann DA, Lobel PS (1998) Acoustic behavior of the damselfish Dascyllus albisella: Behavioral and geographic variation. Environ Biol Fishes 51:421-428

Mann DA, Popper AN, Wilson B (2005) Pacific herring hearing does not include ultrasound. Biol Lett 1:158-161

Matsunaga E, Okanoya K (2009) Evolution and diversity in avian vocal system: An Evo-Devo model from the morphological and behavioral perspectives. Dev Growth Differ 51:355-367 May-Collado LJ, Agnarsson I, Wartzok D (2007) Reexamining the relationship between body 
507 size and tonal signals frequency in whales: A comparative approach using a novel

508 phylogeny. Mar Mammal Sci 23:524-552

509 McComb K, Reby D, Baker L, Moss C, Sayialel S (2003) Long-distance communication of

510 acoustic cues to social identity in African elephants. Anim Behav 65:317-329

511 Mercado E, Herman LM, Pack AA (2005) Song copying by humpback whales: Themes and 512 variations. Anim Cogn 8:93-102

513 Noad MJ, Cato DH, Bryden MM, Jenner M-N, Jenner KCS (2000) Cultural revolution in whale $514 \quad$ songs. Nature 408:537-537

515 Overholtz WJ, Nicolas JR (1979) Apparent feeding by the fin whale, Balaenoptera physalus, and

516 humpback whale, Megaptera novaeangliae, on the American sand lance, Ammodytes

517 americanus, in the northwest Atlantic. Fish Bull 77:285-287

518 Page B, Goldsworthy SD, Hindell MA (2001) Vocal traits of hybrid fur seals: intermediate to 519 their parental species. Anim Behav 61:959-967

520 Parks SE, Clark CW, Tyack PL (2007) Short- and long-term changes in right whale calling 521 behavior: The potential effects of noise on acoustic communication. J Acoust Soc Am $522 \quad 122: 3725-3731$

523 Parks SE, Cusano DA, Bocconcelli A, Friedlaender AS, and Wiley DN (2016). Noise impacts on 524 social sound production by foraging humpback whales. Proc of Meet on Acoust 27: 010009

525 Parsons ECM, Wright AJ, Gore MA (2008) The nature of humpback whale (Megaptera 526 novaeangliae) song. J Mar Anim Their Ecol 1:22-31

527 Payne RS, McVay S (1971) Songs of humpback whales. Science 173:585-97

528 Payne K, Payne R (1985) Large Scale Changes over 19 Years in Songs of Humpback Whales in 529 Bermuda. Ethology 68:89-114

530 Payne PM, Nicolas JR, O'brien L, and Powers KD (1986) The distribution of the humpback 531 whale, Megaptera novaeangliae, on Georges Bank and in the Gulf of Maine in relation to 532 densities of the sand eel, Ammodytes americanu. Fish Bul 84:271-277

533 Petkov CI, Jarvis ED (2012) Birds, primates, and spoken language origins: behavioral

534 phenotypes and neurobiological substrates. Front Evol Neurosci 4:12

535 Pijanowski BC, Villanueva-Rivera LJ, Dumyahn SL, Farina A, Krause BL, Napoletano BM, 536 Gage SH, Pieretti N (2011) Soundscape Ecology: The Science of Sound in the Landscape.

537 Bioscience 61:203-216 
538 Poole JH, Tyack PL, Stoeger-Horwath AS, Watwood S (2005) Animal behaviour: Elephants are 539 capable of vocal learning. Nature 434:455-456

540 Potvin DA, Parris KM, Mulder RA (2011) Geographically pervasive effects of urban noise on 541 frequency and syllable rate of songs and calls in silvereyes (Zosterops lateralis). Proc Biol 542 Sci 278:2464-9

543 R (2013) R Development Core Team. R A Lang Environ Stat Comput 55:275-286

544 Rehn N, Filatova O, Durban J, Foote A (2011) Cross-cultural and cross-ecotype production of a 545 killer whale "excitement" call suggests universality. Naturwissenschaften 98:1-6 546 Rekdahl ML, Dunlop RA, Goldizen AW, Garland EC, Biassoni N, Miller P, Noad MJ (2015) $547 \quad$ Non-song social call bouts of migrating humpback whales. J Acoust Soc Am 137:3042$548 \quad 3053$

549 Rekdahl ML, Dunlop RA, Noad MJ, Goldizen AW (2013) Temporal stability and change in the 550 social call repertoire of migrating humpback whales. J Acoust Soc Am 133:1785-95

551 Rekdahl M, Tisch C, Cerchio S, Rosenbaum H (2016) Common nonsong social calls of 552 humpback whales (Megaptera novaeangliae) recorded off northern Angola, southern 553 Africa. Mar Mammal Sci 33:365-375

554 Richardson WJ, Greene CRJ, Malme CI, Thompson DH (1995) Marine Mammals and Noise. 555 Academic Press, New York

556 Risch D, Clark CW, Corkeron PJ, Elepfandt A, Kovacs KM, Lydersen C, Stirling I, Parijs SM 557 Van (2007) Vocalizations of male bearded seals, Erignathus barbatus: Classification And 558 Geographical Variation. Anim Behav 73:747-762

559 Schilling MR, Seipt I, Weinrich MT, Frohock SE, Kuhlberg AK, and Clapham PJ. (1992)

560 Behavior of individually identified sei whales (Balaenoptera borealis) during an episodic 561 influx into the southern Gulf of Maine in 1986. Fish Bull 90:749-755

562 Sharpe FA (2001) Social foraging of the southeast Alaskan humpback whale, Megaptera $563 \quad$ novaeangliae. $\mathrm{PhD}$ dissertation, Simon Fraser University

564 Silber GK (1986) The relationship of social vocalizations to surface behavior and aggression in 565 the Hawaiian humpback whale (Megaptera novaeangliae). Can J Zool 64:2075-2080

567 Southall BL, Bowles A E, Ellison WT, Finneran JJ, Gentry RL, Greene Jr CR, Kastak, D, 568 Ketten DR, Miller JH, Nachtigall PE and Richardson WJ (2007) Overview. Aquatic 
569 mammals, 33: 411-414.

570 Stimpert AK, Au WWL, Parks SE, Hurst T, Wiley DN (2011) Common humpback whale

571 (Megaptera novaeangliae) sound types for passive acoustic monitoring. J Acoust Soc Am $572 \quad 129: 476-482$

573 Stimpert AK, Peavey LE, Friedlaender AS, Nowacek DP (2012) Humpback Whale Song and

$574 \quad$ Foraging Behavior on an Antarctic Feeding Ground. PLoS One 7:e51214

575 Stimpert AK, Wiley DN, Au WWL, Johnson MP, Arsenault R (2007) "Megapclicks": acoustic

576 click trains and buzzes produced during night-time foraging of humpback whales

577 (Megaptera novaeangliae). Biol Lett 3:467-470

578 Straley JM, Gabriele C, Baker C (1993) Seasonal Characteristics of Humpback Whales

579 (Megaptera novaeangliae) in Southeastern Alaska. Proceeding Third Glacier Bay Sci

$580 \quad$ Symp. 229-238

581 Tibbets EA, Dale J (2007) Individual recognition: it is good to be different. Trends in Ecol. Evo.

$582 \quad 22: 525-537$

583 Thumser NN, Ficken MS (1998) A comparison of the vocal repertoires of captive Spheniscus

584 penguins. Mar Ornithol 26:40-48

585 Tyack P, Sayigh L (1997) Vocal learning in cetaceans. In: Social influences on vocal

586 development. Elsevier, New York

587 Valsecchi E, Palsboll P, Hale P, Glockner-Ferrari D, Ferrari M, Clapham P, Larsen F, Mattila D,

588 Sears R, Sigurjonsson J, Brown M, Corkeron P, Amos B (1997) Microsattelite genetic

589 disrances between oceanic populations of the humpback whale (Megaptera novaeangliae).

$590 \quad 14: 355-362$

591 Vicario DS (2004) Using learned calls to study sensory-motor integration in songbirds. Ann N Y

$592 \quad$ Acad Sci 1016:246-262

593 Weinrich M. (1998) Early experience in habitat choice by humpback whales (Megaptera

594 novaeangliae). J of Mamm 79:163-70

595 Wenz GM (1962) Acoustic Ambient Noise in the Ocean: Spectra and Sources. J Acoust Soc Am $596 \quad 34: 1936$

597 Wickham H (2016) ggplot2: Elegant Graphics for Data Analysis. Springer

$598 \quad$ Verlag New York

599 Wild LA, Gabriele CM (2014) Putative contact calls made by humpback whales (Megaptera 
600 novaeangliae) in southeastern Alaska. Can Acoust 42:23-31

601 Winn HE, Thompson TJ, Cummings WC, Hain J, Hudnall J, Hays H, Steiner WW, (1981) Song

602 of the Humpback Whale: Population Comparisons. Behav Ecol Sociobiol 8:41-46

603 Zann R (2010) Ontogeny of the Zebra Finch Distance Call: I. Effects of Cross-fostering to

$604 \quad$ Bengalese Finches. Z Tierpsychol 68:1-23

605 


\section{Figure 1}

Map of (A) Southeast Alaska, North Pacific recording locations and (B) Massachusetts Bay, North Atlantic recording locations. (Map data (c2016 Google)

Red area indicates sampling region for hydrophone recordings made in 1976. Stars in both maps indicate moored hydrophone locations. 

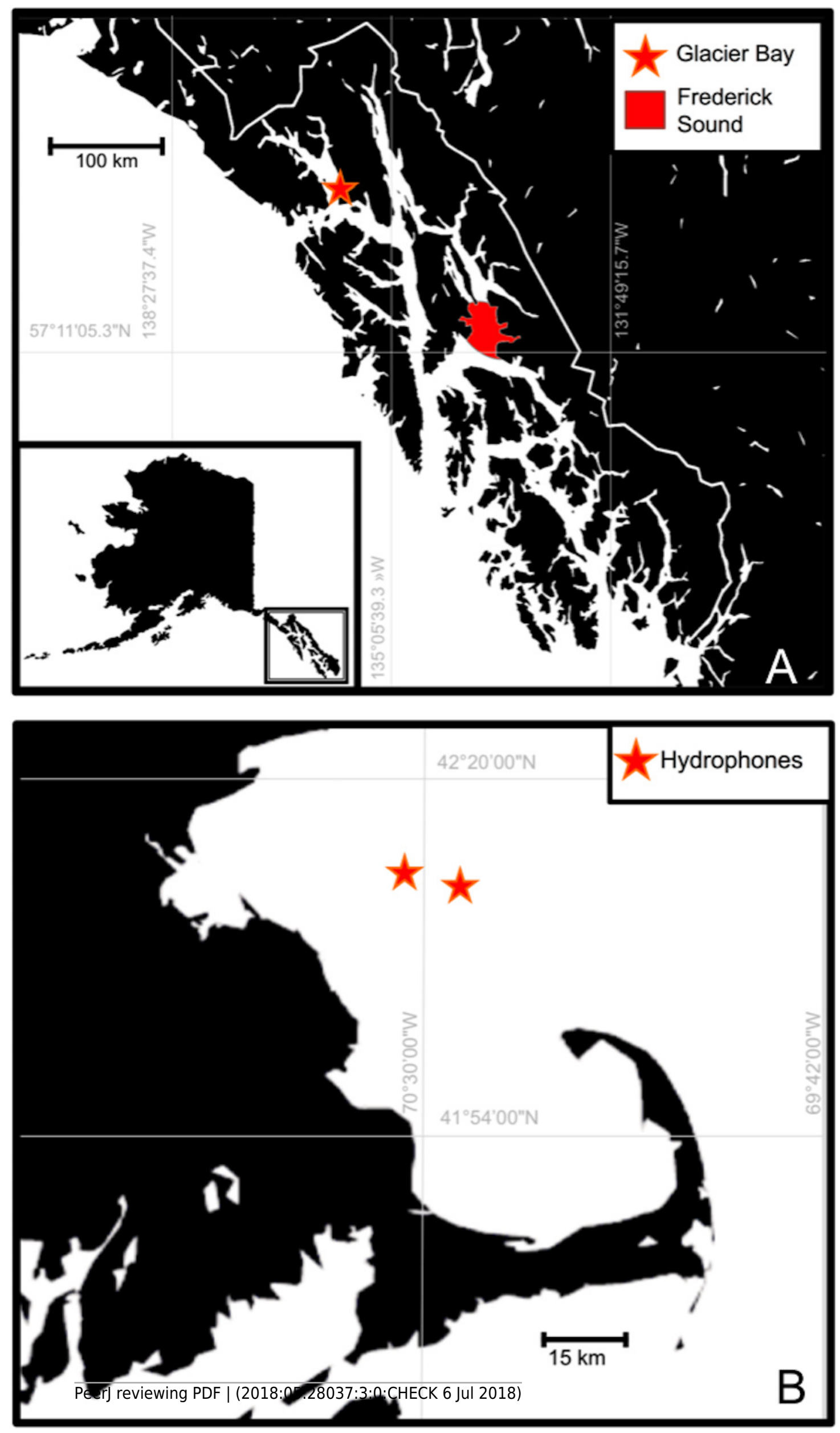
Figure 2

Spectrograms of call types by ocean basin (FFT 256, Hann window, 90\% overlap).

Call types: (A) swops, (B) whups and growls, (C) teepees, (D) droplets. The horizontal lines at $\sim 500$ and $800 \mathrm{~Hz}$ in spectrograms from the Atlantic indicate vessel noise.

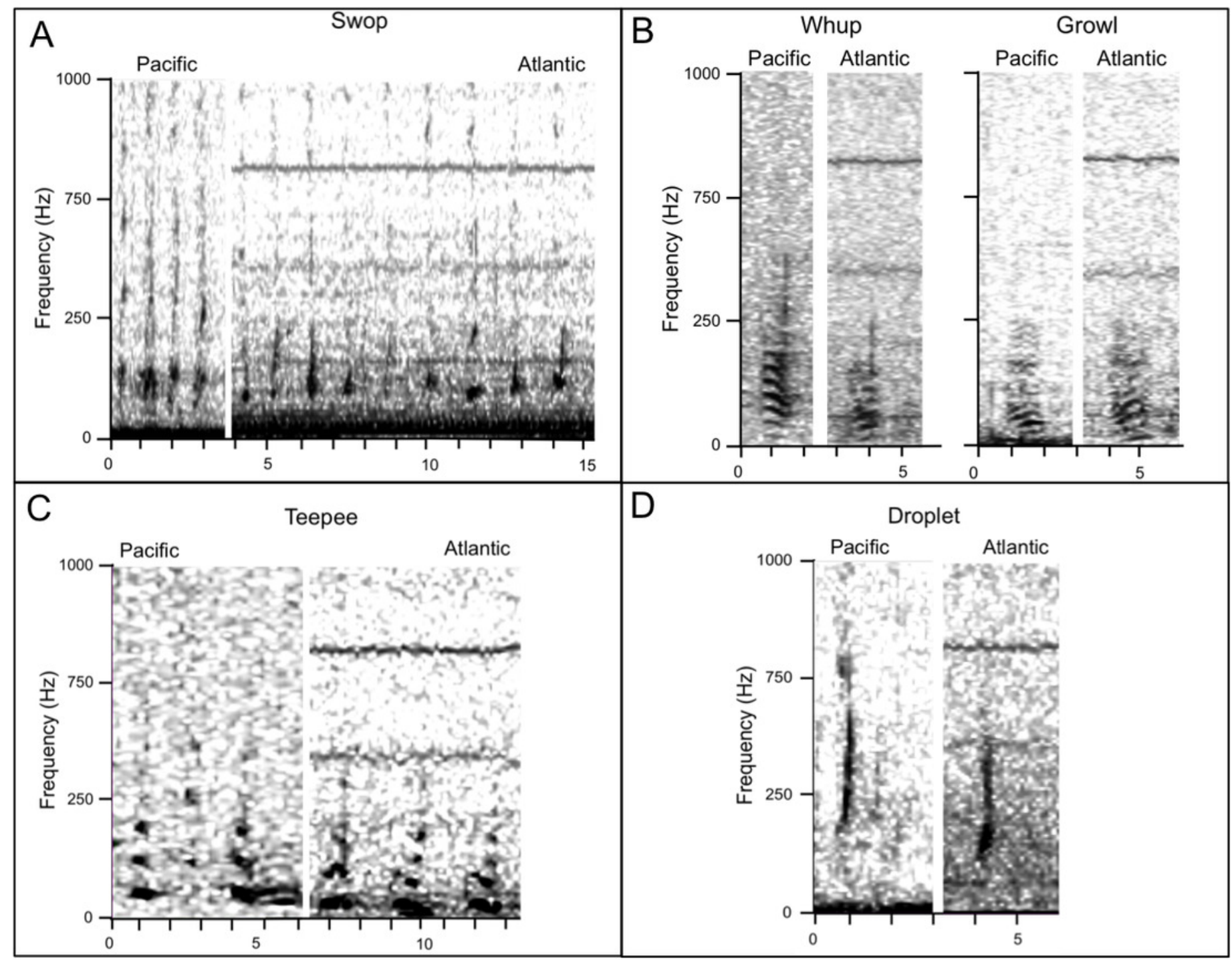

Time (s) 
Figure 3

Boxplots of $\mathrm{PC} 1$ values (indicative of entropy, bandwidth, and upper frequency components) between call types and ocean basins.

Calls recorded in the Atlantic Ocean are indicated by coral, and the Pacific ocean by teal. Call types: (A) Droplet (B) Growl (C) Swop (D) Teepee (E) Whup. Boxplots illustrate median, first, and third quartile PC1 values; dots indicate outliers. 


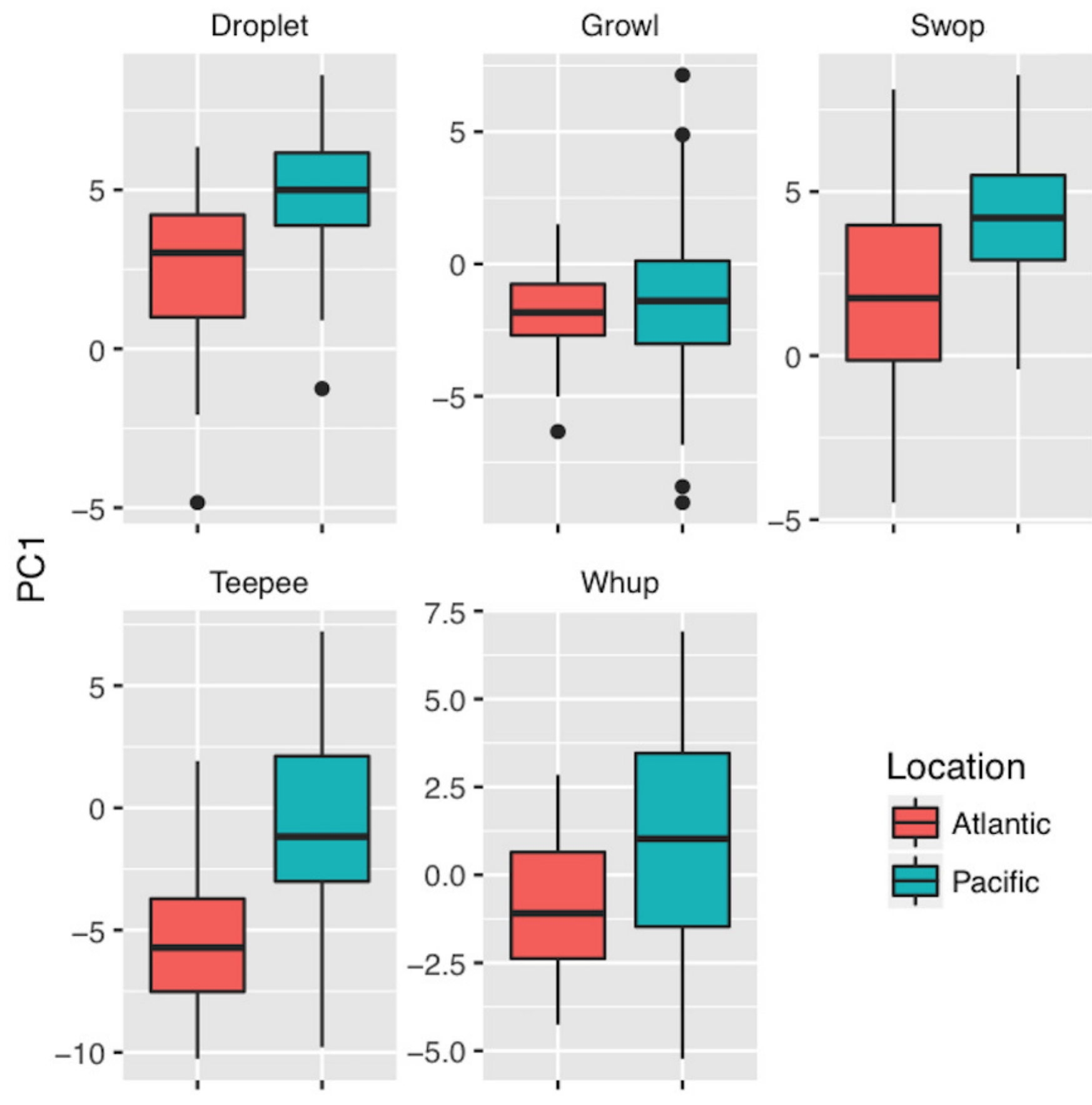


Figure 4

Boxplot of PC2 values (indicative of lower frequency, start frequency, and peak frequency components) between call types and ocean basins.

Calls from the Atlantic are indicated by coral, calls from the Pacific are indicated by teal. Call types: (A) Droplet (B) Growl (C) Swop (D) Teepee (E) Whup. Boxplots illustrate median, first, and third quartile PC2 values; dots indicate outliers. 


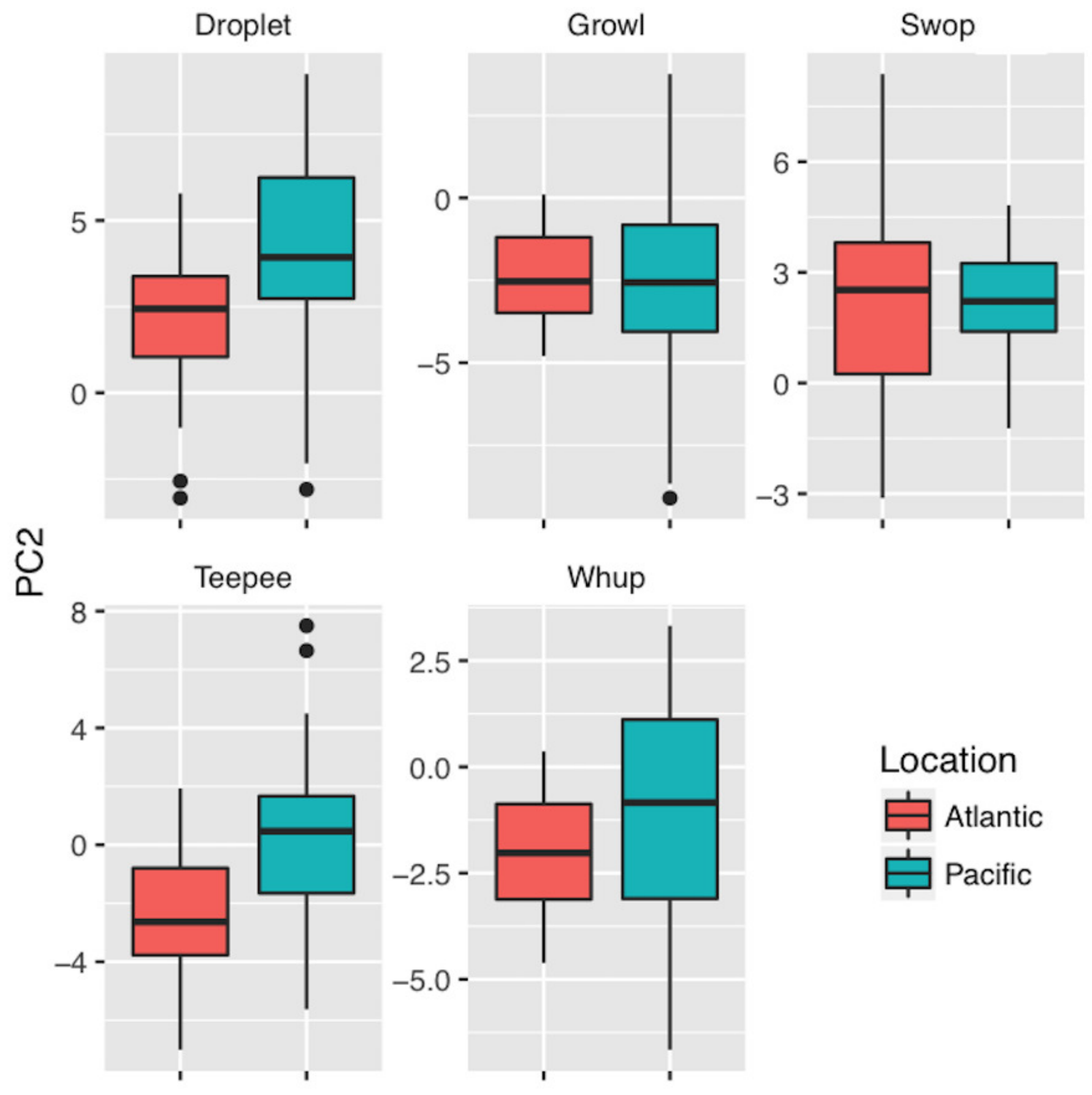




\section{Table 1 (on next page)}

Recordings specifications for data collection protocols from North Pacific and North Atlantic foraging grounds. 
1 Table 1-Recordings specifications for data collection protocols from North Pacific and North Atlantic foraging grounds.

\begin{tabular}{|c|c|c|c|}
\hline Year & 1976 & $2007 \& 2008$ & 2008 \\
\hline Hydrophone model & Unknown & ITC $8215 \mathrm{~A}$ & HTI-94-SSQ \\
\hline Sampling rate & $44.1 \mathrm{kHz}$ & $44.1 \mathrm{kHz}$ & $2 \mathrm{kHz}$ \\
\hline System sensitivity & Unavailable & $\begin{array}{c}-174 \mathrm{~dB} \pm 2 \mathrm{~dB} \text { re } 1 \\
V / \mu \mathrm{Pa}\end{array}$ & $\begin{array}{c}-168 \mathrm{~dB} \pm 1 \mathrm{~dB} \text { re } 1 \\
\mathrm{~V} / \mu \mathrm{Pa}\end{array}$ \\
\hline Deployment method & $\begin{array}{l}\text { Dipping } \\
(20 \mathrm{~m})\end{array}$ & $\begin{array}{l}\text { Bottom-mounted } \\
\qquad(52 \mathrm{~m})\end{array}$ & $\begin{array}{l}\text { Bottom-mounted } \\
\qquad(\sim 60 \mathrm{~m})\end{array}$ \\
\hline Location & $\begin{array}{l}\text { Frederick } \\
\text { Sound }\end{array}$ & Glacier Bay & $\begin{array}{c}\text { Stellwagen Bank National } \\
\text { Marine Sanctuary }\end{array}$ \\
\hline Recording cycle & $\begin{array}{c}\text { Non- } \\
\text { standardized }\end{array}$ & $\begin{array}{l}30 \text { seconds from every } \\
\text { hour }\end{array}$ & Continuous \\
\hline Data format & Continuous & 30 -second recordings & 5-minute recordings \\
\hline Recording Days & 4 & 72 & 10 \\
\hline Date Range & July 1976 & $\begin{array}{l}\text { June-September } 2007 \\
\text { June-September } 2008\end{array}$ & June-August 2008 \\
\hline
\end{tabular}

2

3

4 


\section{Table 2 (on next page)}

Acoustic parameters used in Classification and Regression Tree (CART) analysis.

Log transformed parameters are indicated with an asterisk $(*)$. 
1

\begin{tabular}{|c|c|}
\hline Duration $(90 \%)(\mathrm{s})$ & $90 \%$ of the duration of the annotated call \\
\hline Bout & Number of repetitions of the same call type \\
\hline Low Frequency $(\mathrm{Hz})^{*}$ & Lowest frequency component of the call \\
\hline High Frequency $(\mathrm{Hz})^{*}$ & Highest frequency component of the call \\
\hline Bandwidth $(90 \%)(\mathrm{Hz})$ & $\begin{array}{l}90 \% \text { of the difference in frequency between high } \\
\text { and low frequency }\end{array}$ \\
\hline Start Frequency $(\mathrm{Hz})^{*}$ & Starting frequency of fundamental \\
\hline End Frequency $(\mathrm{Hz})^{*}$ & Ending frequency of fundamental \\
\hline Peak Frequency $(\mathrm{Hz})^{*}$ & Frequency of the spectral peak \\
\hline Center Frequency $(\mathrm{Hz})^{*}$ & $\begin{array}{l}\text { The frequency that divides the sound equally into } \\
\text { two intervals of equal energy }\end{array}$ \\
\hline Frequency Trend* & Start $\mathrm{F}_{0} /$ End $\mathrm{F}_{0}$ \\
\hline Aggregate Entropy (bits) & $\begin{array}{l}\text { A measure of total disorder in the call (RavenPro, } \\
1.5)\end{array}$ \\
\hline
\end{tabular}

2 


\section{Table 3 (on next page)}

Summary statistics (mean in bold, standard deviation) for call parameters by call type and location. 
1 Table 3-Summary statistics (mean in bold, standard deviation) for call parameters by call type and location.

\begin{tabular}{|c|c|c|c|c|c|c|}
\hline \multicolumn{2}{|c|}{ Type } & Variable & \multicolumn{2}{|c|}{ Atlantic } & \multicolumn{2}{|c|}{ Pacific } \\
\hline \multirow{8}{*}{ 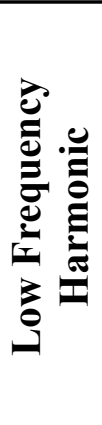 } & \multirow{4}{*}{ 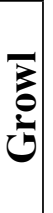 } & $\mathbf{N}$ & \multicolumn{2}{|c|}{41} & \multicolumn{2}{|c|}{78} \\
\hline & & Low Freq (Hz) & \multicolumn{2}{|l|}{41} & \multicolumn{2}{|r|}{21.8} \\
\hline & & Peak Freq (Hz) & 87.4 & 15.1 & 116 & 62.6 \\
\hline & & Duration (s) & 0.8 & 0.24 & 0.7 & 0.3 \\
\hline & \multirow{4}{*}{$\frac{0}{3}$} & $\mathbf{N}$ & \multicolumn{2}{|c|}{21} & \multicolumn{2}{|c|}{36} \\
\hline & & Low Freq (Hz) & 49.9 & 15.8 & 47.4 & 25.1 \\
\hline & & Peak Freq (Hz) & 94.9 & 26.2 & 128 & 70.3 \\
\hline & & Duration (s) & 0.6 & 0.18 & 0.7 & 0.2 \\
\hline \multirow{12}{*}{ 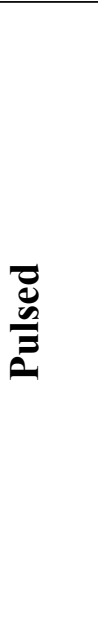 } & \multirow{4}{*}{$\begin{array}{l}\frac{\pi}{0} \\
\overline{0} \\
\overline{0} \\
0\end{array}$} & $\mathbf{N}$ & \multicolumn{2}{|c|}{44} & \multicolumn{2}{|c|}{29} \\
\hline & & Low Freq (Hz) & 99.4 & 49 & 148 & 99.8 \\
\hline & & Peak Freq (Hz) & 187 & 62.6 & 252 & 120 \\
\hline & & Duration (s) & 0.4 & 0.2 & 0.3 & 0.16 \\
\hline & \multirow{4}{*}{ 号 } & $\mathbf{N}$ & \multicolumn{2}{|c|}{45} & \multicolumn{2}{|c|}{16} \\
\hline & & Low Freq (Hz) & 76.5 & 31.4 & 70 & 30 \\
\hline & & Peak Freq (Hz) & 159 & 54.3 & 214 & 85.6 \\
\hline & & Duration (s) & 3.9 & 4.2 & 0.3 & 0.2 \\
\hline & \multirow{4}{*}{ 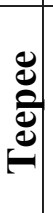 } & $\mathbf{N}$ & \multicolumn{2}{|c|}{40} & \multicolumn{2}{|c|}{51} \\
\hline & & Low Freq (Hz) & 40 & 17 & 214 & 25.1 \\
\hline & & Peak Freq (Hz) & 79.2 & 28.8 & 154 & 70.3 \\
\hline & & Duration (s) & 1.1 & 1.77 & 0.4 & 0.23 \\
\hline
\end{tabular}

2 


\section{Table 4 (on next page)}

Confusion matrix indicating agreement between (vertical) Classification and Regression Tree call type assignment versus (horizontal) human call type assignment. 
1 Table 4- Confusion matrix indicating agreement between (vertical) Classification and Regression Tree call type assignment versus (horizontal) human call type assignment.

\begin{tabular}{|c|c|c|c|c|c|c|c|}
\hline & Droplet & Feed & Growl & $\begin{array}{l}\text { Swop } \\
\text { s }\end{array}$ & Teepee & Whup & Agreement \\
\hline Droplet & 58 & 0 & 3 & 5 & 4 & 3 & $79 \%$ \\
\hline Feed & 0 & 10 & 0 & 0 & 0 & 0 & $100 \%$ \\
\hline Growl & 0 & 0 & 111 & 1 & 3 & 4 & $93 \%$ \\
\hline Swops & 5 & 0 & 1 & 44 & 9 & 2 & $72 \%$ \\
\hline Teepee & 3 & 0 & 3 & 4 & 81 & 0 & $89 \%$ \\
\hline Whup & 2 & 0 & 22 & 2 & 0 & 31 & $54 \%$ \\
\hline & & & & & $\begin{array}{r}T \\
\text { Agre }\end{array}$ & ment & $82 \%$ \\
\hline
\end{tabular}

3 